\title{
A ATUAÇÃO BRASILEIRA NA GOVERNANÇA DA INTERNET
}

\author{
Jaqueline Trevisan Pigatto
}

\section{Resumo}

Este artigo faz uma breve análise da recente atuação do Brasil na Governança da Internet, a partir das denúncias de espionagem norte-americanas por Edward Snowden, em 2013. Tendo alcançado relativo sucesso com uma política autônoma no primeiro mandato do governo Rousseff, hoje a questão é posta em xeque, principalmente no âmbito interno, em relação ao uso e normas da Internet. Faz-se, também, uma análise da posição brasileira pré-Snowden e da atuação do CD Ciber. Nota-se que a descentralização da Internet é o principal objetivo dos atores que lutam por mudanças.

Palavras-chave: Governança da Internet - Marco Civil - multissetorialismo.

\section{Abstract}

This article is a brief analysis of the Brazil's recent performance on the issue of Internet Governance, since the spy allegations of Edward Snowden in 2013. Having achieved relative success with an autonomous policy in the first Rousseff's government, today the question is open, especially at the national level,

\footnotetext{
${ }^{1}$ Graduanda em Relações Internacionais pela Universidade Estadual Paulista (UNESP) - campus Franca. Este artigo é parte da pesquisa em Iniciação Científica "O Brasil e a Governança da Internet: a repercussão do caso Snowden e as ações do governo brasileiro por maior controle internacional da rede", financiada pela Fundação de Amparo à Pesquisa do Estado de São Paulo (FAPESP).
} 
regarding Internet's use and standards. This brings also an analysis of the Brazilian position pre-Snowden and the CD Ciber performance. It is notable that the decentralization of the Internet is the main objective of the actors who fight for changes.

Key-words: Internet Governance - Marco Civil - Multistakeholder.

\section{Introdução}

Como parte da busca de projeção internacional brasileira, a exemplo do objetivo de um assento no Conselho de Segurança da ONU, o Brasil vem se mostrando atuante nos assuntos cibernéticos. A partir da singularidade do país, quinto maior do mundo, com um crescente número de usuários da rede, o Brasil busca consolidar sua liderança regional e destacar-se no cenário internacional, seja através de políticas autônomas ou parcerias com outros países emergentes que fujam da submissão aos países do Norte, como os BRICS.

Destacam-se as conquistas do Estado brasileiro, juntamente com a sociedade civil, desde o caso Snowden, em 2013. As maiores são o Marco Civil da Internet, aprovado em 2014, e a transição da ICANN, que embora não esteja diretamente relacionada com as atividades de espionagem, pode ser entendida como uma resposta do governo Obama frente aos pedidos por uma descentralização da rede, até então subordinada aos Estados Unidos.

Desse modo, este artigo visa contribuir para as análises sobre o tema, a partir da área de Relações Internacionais, campo no qual a Internet ainda é pouco estudada. $\mathrm{O}$ recorte do trabalho tem seu foco na gestão Rousseff, especialmente no início de seu 
segundo mandato, já que especialistas em política externa ainda não escreveram tanto sobre o papel brasileiro na Governança da Internet.

\section{Desenvolvimento}

Apesar da grande preocupação do governo e da sociedade civil com o uso da Internet, apenas metade do país possui acesso, dado que a administração Rousseff procurou reverter com projetos de inclusão digital (PORTAL BRASIL, 2016). O uso da rede no país também é forte por parte do próprio governo, que busca facilitar a comunicação com a população, a exemplo do texto do Marco Civil da Internet, que foi posto para discussão no início de 2016. Foram recebidos da sociedade 1524 comentários, sendo a questão da neutralidade da rede a mais comentada. O tema de proteção aos registros, aos dados pessoais e às comunicações privadas foi o segundo mais comentado (MINISTÉRIO DA JUSTIÇA, 2016).

Tendo em vista a preocupação brasileira com a regulamentação da Internet, especialmente após descoberta a espionagem que o governo estadunidense mantinha sobre alguns Estados, inclusive o Brasil, o Marco Civil foi elaborado como um documento do âmbito doméstico que se tornou exemplo para todo o mundo. $\mathrm{O}$ documento prima pela neutralidade da rede, ou seja, as operadoras não podem cobrar custos diferenciados dependendo do uso que se faz da Internet, como acesso a vídeos e compartilhamento de arquivos. Também garante a liberdade de expressão e a proteção da privacidade (com indenização em caso de violação), além de proibir o acesso de terceiros a correspondências e dados. Quanto aos casos de espionagem, o documento tornou ilegal a cooperação de empresas de Internet com órgãos de inteligência estrangeiros.

Sobre o documento, a presidente Dilma Rousseff declarou: 
Temos que ter consciência de que o Brasil nessa área, é protagonista nesse novo mundo da internet. Nós não somos protagonistas apenas porque temos uma extraordinária participação da nossa população na internet, nós somos, sem dúvida nenhuma, usuários destacados dos novos meios de comunicação, mas nós queremos também ser protagonistas porque temos um Marco Civil avançado, que contemplou e foi construído, aliás, de forma participativa e que contemplou e deu regras claras à internet, garantindo a liberdade de expressão, garantindo uma modificação na concepção, inclusive internacional, de Marco Civil. Essas regras claras são muito importantes porque protegem a privacidade dos cidadãos, estabelece também o que pode e o que não pode ser retirado de conteúdo na rede. Agora nós estamos e abrimos um processo de discussão que é a consulta pública que vai propiciar a regulamentação do Marco Civil, que é a nossa Constituição no mundo offline [online]. Convido a todos a participar desse processo para regulamentação. Porque esse espaço para nós deve ser, cada vez mais, um território da cidadania, da colaboração e da paz (FUNAG, 2016).

O documento, primeiro do tipo em todo o mundo, foi uma iniciativa da Secretaria de Assuntos Legislativos do Ministério da Justiça em parceria com o Centro de Tecnologia e Sociedade da Fundação Getúlio Vargas (FGV) do Rio de Janeiro. Ele esclarece a posição do Brasil sobre uso e regulamentação da Internet, ao primar pelas liberdades e direitos civis, que são bases para uma governança mundial. Em outros países, existem legislações sobre alguns pontos do uso da rede, mas não uma "constituição" como o Marco Civil. A Espanha, por exemplo, possui uma lei sobre Propriedade Intelectual de 2012, que visa o combate à pirataria e uma economia produtiva e competitiva. Uma lei semelhante foi promulgada na França ainda em 2009, a Lei de Criação e Internet, ou Lei Hadopi.

Em dezembro de 2012, a União Internacional de Telecomunicações (UIT) realizou uma conferência mundial em Dubai, onde discutiu-se a questão da regulação da Internet, se deveria ser feita no âmbito da ONU e através de um tratado. Surpreendentemente, à época o Brasil se posicionou ao lado de Irã e China, a favor de uma regulamentação com participação apenas dos governos (tal acontecimento ocorre 1 ano 
antes das denúncias de Snowden). Além disso, a resolução aprovava uma "inspeção profunda de pacotes", uma ferramenta para espionar cidadãos, o que causou muita polêmica (FOLHA, 2013). O documento oficial da conferência, entretanto, reconhece a importância de consulta aos outros atores para além dos Estados:

That, as stated in the WSIS outcomes, all governments should have an equal role and responsibility for international Internet governance and for ensuring the stability, security and continuity of the existing Internet and its future development and of the future internet, and that the need for development of public policy by governments in consultation with all stakeholders is also recognized. (ITU - Final Acts Of The World Conference On International Telecommunications, 2012, p.20)

Nota-se, portanto, que o governo brasileiro já assumiu posição divergente com a que se assume atualmente. Descobriu-se, também, que o governo brasileiro já monitorou sua população, em caso semelhante ao que ocorre nos Estados Unidos, segundo as revelações de Snowden. O interesse brasileiro no ciberespaço provém da Estratégia de Defesa Nacional (NSD), no segundo governo Lula da Silva. O Brasil criou em 2009 o CDCiber (Centro de Defesa Cibernética), o primeiro do tipo na América Latina, com o objetivo principal de defesa de ataques tanto internos quanto externos. Coordenado com o Ministério da Defesa, o Centro possui um simulador de ciberguerra e especialistas que recebem treinamento em cibersegurança (MUGGAH; GLENN; DINIZ, 2014). Visando também os megaeventos, o CDCiber fez sua "estreia" na Rio+20, a conferência climática da ONU em 2012, sediada no Rio de Janeiro (PORTAL G1, 2016). Houve na ocasião, porém, um ataque do grupo de hacker Anonymous (PORTAL G1, 2016).

O CDCiber atua constantemente no monitoramento da Internet brasileira, o que causa controvérsias com a posição de defesa da rede do próprio governo:

Naturalmente, o governo brasileiro não é totalmente inocente no tocante à ciberespionagem. Ao passo que as autoridades do país expressaram sua indignação contra a vigilância pela NSA, foram autorizados ABIN e CDCiber os responsáveis pela proteção do país precisamente contra este tipo de 
interferência - a monitorar as atividades das mídias sociais no Brasil relativas aos protestos em massa de junho a agosto de 2013. A ABIN recebeu críticas por não antecipar os eventos que deram origem aos protestos de 2013. Mesmo assim, a ABIN introduziu a plataforma Mosaico, de monitoramento da mídia social, para rastrear usuários e se adiantar aos novos acontecimentos. O sistema de monitoramento é controverso aos olhos de alguns ativistas da Internet, pois poderá levar à autocensura bem como a pressões sobre os movimentos sociais legítimos. (MUGGAH; GLENN; DINIZ, 2014, p.86)

Embora a principal preocupação do governo seja cibercrimes de motivação econômica (pouco mais de $43 \%$ dos usuários da Internet utilizam serviços bancários online), a atividade de hackers é também visada, a exemplo do período de junho de 2013, quando dos protestos populares que ocorreram no país. Mas outra situação, a qual não se deve confundir com a espionagem, e que é utilizada pelo CD Ciber em parceria com a ABIN (Agência de Inteligencia Brasileira) desde 2013, é o monitoramento de redes sociais. Tal atividade não está infringindo privacidade, já que os usuários têm liberdades de postarem o que quiserem na rede, onde naturalmente surgem opiniões e posições sobre diversos temas, como política, religião, extremismo, racismo, entre outros. Assim, a discussão da cibersegurança deveria ser levada à população, assim como a discussão da Governança da Internet e seus subtemas como censura, liberdade de expressão e neutralidade da rede. A transparência deve prevalecer acima de quaisquer políticas, o que, sem dúvida, mostraria um grande avanço frente aos Estados Unidos e outros países que estejam com essa pauta em suas agendas.

Outra contradição no uso da rede brasileira foram os recentes casos de bloqueio do Whatsapp (PORTAL G1, 2016), aplicativo de troca de mensagens por celular, pertencente ao Facebook. Extremamente popular no país, o serviço ficou fora do ar pela primeira vez por 12 horas a mando de uma juíza que alegou que a empresa não forneceu dados e registros de conversas para uma investigação do Ministério Público. A medida, que deveria durar 48 horas, foi revertida por outro juiz, que sugeriu uma multa ao 
Facebook. O caso voltou a se repetir no início de maio desse ano. Esse fato causou perplexidade no Brasil e fora, já que o país do Marco Civil, que busca proteger as liberdades e privacidade de seus cidadãos, teve um de seus serviços facilmente "derrubado" por autoridades nacionais. Esse caso ressalta a importância da busca de um equilíbrio entre a Internet aberta e a vigilância de seus usuários.

Portanto, a ciberespionagem é um dos, se não o principal motivo de uma regulamentação mais eficaz e unificada da rede, tanto nas relações internacionais quanto no âmbito doméstico. Um exemplo é o tratado bilateral entre Brasil e Rússia de Não Agressão com Armas de Informática, o primeiro do tipo: "Além de resultar no tratado de não agressão, o mesmo dispõe do intercâmbio aperfeiçoado de informações, fortalecimento de capacidade e exercícios conjuntos de ciberguerra" (MUGGAH; GLENN; DINIZ, 2014, p.104). Tal acordo abre precedente para maior parceria dentro dos BRICS.

Visto que o Brasil tem essa preocupação com o uso da rede e procurou primeiro trabalhá-la no âmbito interno, houve uma transferência da preocupação doméstica para o nível internacional, em uma série de medidas que podem ser vistas como respostas às denúncias de Snowden, onde o Brasil foi um dos principais alvos dos Estados Unidos, que visavam vantagens econômicas e diplomáticas.

Assim, a postura brasileira com relação a espionagem e proteção dos direitos humanos online surgiu forte em 2013, com destaque para o discurso de abertura da $68^{\mathrm{a}}$ Assembleia Geral da ONU, da presidente Dilma Rousseff (TV NBR, 2013):

O Brasil redobrará os esforços para dotar-se de legislação, tecnologia e mecanismos que nos protejam da interceptação ilegal de comunicações e dados. Meu governo fará tudo que estiver ao seu alcance para defender os Direitos Humanos de todos os brasileiros e de todos os cidadãos do mundo e proteger os frutos da engenhosidade dos trabalhadores e das empresas brasileiras. 
Tais propostas não deixaram de ser alcançadas, tendo em vista a aprovação do Marco Civil da Internet em 2014, modelo mundial de legislação para uso da rede. A presidente evidenciou a dimensão e urgência do tema para as relações internacionais, ainda no mesmo discurso, enfatizando a necessidade do multilateralismo (e ainda não, naquele momento, do multissetorialismo):

\begin{abstract}
As tecnologias de informação e comunicação não podem ser o novo campo de batalha entre os Estados. Esse é o momento de criarmos as condições para evitar que o espaço cibernético seja instrumentalizado como arma de guerra, por meio da espionagem, da sabotagem, dos ataques contra sistemas e infraestrutura de outros países. A ONU deve desempenhar um papel de liderança no esforço de regular o comportamento dos Estados frente a essas tecnologias, e a importância da Internet, dessa rede social, para a construção da democracia no mundo.
\end{abstract}

Já no discurso do ano seguinte, a presidente Dilma Rousseff falou do caráter multissetorial presente na NETMundial e, assim, destacou sua importância e a adesão de outros países na busca de um novo modelo de governança para a Internet:

Em setembro de 2013, propus aqui, no debate geral, a criação de um marco civil para a governança e o uso da Internet com base nos princípios da liberdade de expressão, da privacidade, da neutralidade da rede e da diversidade cultural. Noto, com satisfação, que a comunidade internacional tem se mobilizado, desde então, para aprimorar a atual arquitetura de governança da internet. Passo importante nesse processo foi a realização, por iniciativa do Brasil, da Reunião Multissetorial Global sobre o Futuro da Governança da Internet - a NETmundial - em São Paulo, em abril deste ano. O evento reuniu representantes de várias regiões do mundo e de diversos setores. Foram discutidos os princípios a seguir e as ações a empreender para garantir que a internet continue a evoluir de forma aberta, democrática, livre, multissetorial e multilateral (ROUSSEFF, 2014).

Os esforços brasileiros, entretanto, não foram suficientesfrente aos Estados Unidos, já que outros países não quiseram se comprometer em opor o (ainda) Estado mais relevante da política internacional: 


\begin{abstract}
A meta do Itamaraty era a de ter um documento que condenasse a prática dos EUA, com apoio de vários continentes, a fim de constranger a Casa Branca a dar explicações. Mas desde o início ficou claro que a tarefa não seria fácil. Mesmo tendo sido alvo da espionagem, governos europeus preferiram soluções como promover seminários sobre o tema a relação com a proteção à liberdade de expressão - caso de Alemanha e Noruega. (CHADE, 2013, Estadão)
\end{abstract}

Em 2015, o episódio da espionagem e o esfriamento das relações Brasil-EUA parece ter sido superado, em encontro dos presidentes Barack Obama e Dilma Rousseff na Cidade do Panamá. Após a retomada dos diálogos, o governo brasileiro passou a imagem de que tudo estava certo entre os dois países, apesar de não ter acontecido um pedido formal de desculpas por parte do governo norte-americano. A promessa de transição das funções da $\mathrm{ICANN}^{2}$, por vezes adiada no governo Obama, foi um passo rumo às transformações do cenário cibernético, tendo seu processo concluído em $1^{\circ}$ de outubro de 2016. No Panamá, a presidente declarou:

O governo americano não disse só para o Brasil, mas disse para todos os países do mundo que os países amigos, os países irmãos, não seriam espionados. E também uma declaração do presidente Obama, ele falou pra mim que quando ele quiser saber qualquer coisa, ele liga pra mim. (Eu) não só atendo, como fico muito feliz (O GLOBO, 2015).

Sobre a transição da ICANN, o secretário-executivo do Comitê Gestor da Internet no Brasil (CGI.br) Hertmut Glaser explica, destacando a atuação brasileira:

Houve vários incidentes e um que o Brasil participou muito ativamente foi a realização do evento chamado NetMundial. O NetMundial foi uma forma que o Brasil procurou de marcar uma posição contra a espionagem, Snowden e aquela história toda. O presidente da ICANN, Fadi Chehade, visitou a presidente Dilma

\footnotetext{
${ }^{2}$ Entidade de caráter privado, mas que está subordinada às leis dos EUA, atuando na definição de regras aplicáveis globalmente sobre o sistema de nomes e números da Internet.
} 
e os dois entraram em acordo de convocar para abril de 2014 uma reunião internacional para decidir alguns princípios de governança da internet. A própria IANA e o pessoal nos Estados Unidos se sentiu meio ameaçado com essa discussão, não se sabia o que ia acontecer, e anunciaram que estavam prontos para começar o estudo de uma transição da função IANA (CONVERGÊNCIA DIGITAL, 2016).

Observa-se, assim, como o Brasil chamou a atenção para a criação de uma governança ou medidas mais drásticas no ambiente cibernético. Nesse contexto, o país sediou em novembro de 2015 o IGF (Fórum de Governança da Internet), uma plataforma da ONU para diálogo entre os setores interessados na governança da rede. O evento ocorre anualmente desde 2006, e já havia ocorrido no Brasil em 2007. Totalmente aberto, qualquer pessoa, entidade, empresa ou governo pode participar dos debates, o que evidencia uma evolução na questão da Internet. O IGF 2015, realizado em João Pessoa, priorizou temas como a neutralidade da rede e a transição da ICANN, já citada (PB AGORA, 2015).

Em 2014, à luz do discurso da presidente Dilma Rousseff na Assembleia Geral da ONU, Brasil e Alemanha conseguiram aprovar uma resolução sobre privacidade na era digital, inclusive no Conselho de Direitos Humanos, em Genebra. O documento também reconhece a "natureza global e aberta da Internet e do rápido avanço da tecnologia da informação e comunicação como uma força motriz para acelerar o progresso rumo ao desenvolvimento em suas várias formas” (ONU BRASIL, 2015).

Portanto, o tema Governança da Internet vem crescendo mundialmente, mas ganha importância especialmente no Brasil, ao mostrar-se uma oportunidade para o país aumentar seu prestígio no cenário internacional e abrir caminhos para se tornar um global player, de fato, especialmente com a oposição aos Estados Unidos causada em 2013 (THE GUARDIAN, 2013). Desde o Wikileaks, o assunto também cresceu internamente, despertando um maior questionamento da população sobre uso da Internet e maiores e 
mais profundas atividades de jornalismo investigativo. O tema também é, claramente, uma nova pauta da agenda internacional, atraindo políticos, internacionalistas, acadêmicos e diversas outras partes interessadas. A transparência se tornou palavra-chave no Brasil, a partir de fatos como vazamento de informações e acesso a documentos governamentais, tendo como uma consequência, por exemplo, a Lei de Liberdade de Acesso ${ }^{3}$, de 2011, tornando-se um marco histórico brasileiro, além do mundialmente elogiado Marco Civil, já mencionado. Julian Assange (TED TALKS, 2010) declarousobre o futuro que tomaria a vigilância e o controle:

\begin{abstract}
I'm not sure which way it's gonna go. There are enormous pressures to harmonize freedom of speech, legislation and transparecy legislation around the world. Within EU, between China, United States, which way it's gonna go, it's hard to see. That's why is a very interesting time to be in, because with a little bit of effort, we can shif it one way or the other.
\end{abstract}

No final de março de 2016, o Brasil voltou a se preocupar com o futuro de sua Internet, devido a projetos de lei que buscam alterar o Marco Civil. O Relatório Final da CPI de Crimes Cibernéticos (CÂMARA, 2016) propõe atuação da Polícia Federal em crimes cibernéticos; multa e pena de prisão ao "uso indevido da Internet", o que leva a questão do que seria exatamente esse uso; retirada de conteúdos que atentem contra a honra, com responsabilidade de provedores e redes sociais, que abre margem para censura e vai totalmente contra o ponto de liberdade de expressão do Marco Civil; entre outras questões polêmicas. O documento ainda está em tramitação e deve seguir para a Câmara dos Deputados. O Comitê Gestor da Internet no Brasil (CGI.br) divulgou uma nota de esclarecimento referente ao relatório (CGI, 2016), onde manifesta grande preocupação com as modificações propostas, reiterando a importância dos "princípios da liberdade de

\footnotetext{
${ }^{3}$ Acesso a Informação. Governo Federal. Para saber mais: 〈http://www.acessoainformacao.gov.br/>. Acesso em 16 mar 2016.
} 
expressão, da privacidade dos cidadãos e da preservação da funcionalidade e estabilidade da rede, em plena consonância com o já estabelecido na Lei 12.965/2014”.

A política externa de Rousseff, especialmente em seu primeiro mandato, fica, então, caracterizada por grande autonomia, tendo em vista os desdobramentos do escândalo de espionagem. A discussão conseguiu atingir um alto nível de preocupação e ações globais de diversos atores. Apesar de internamente o Brasil ainda enfrentar dificuldades com o Marco Civil, têm-se no âmbito externo a transição da ICANN, concluída em $1^{\circ}$ de outubro de 2016 , como um dos legados da reação brasileira sobre a espionagem estadunidense. Para Carlos Ferreira (2014):

\begin{abstract}
Tem-se aqui outro exemplo de uma política altiva e ativa: por um lado, o País não se calou - como era de se esperar em governos anteriores - diante da violação de padrões de conduta internacional promovida pela grande potência mundial. Por outro, o governo deu passos significativos para promover uma solução à questão, a exemplo "da iniciativa do Brasil, da Reunião Multissetorial Global sobre o Futuro da Governança da Internet - a NETmundial", que ocorreu em abril deste ano, como sustentou a presidenta.
\end{abstract}

Uma possibilidade de maior oposição ao regime da ICANN, por exemplo, poderia partir dos BRICS, já que são países de destaque no cenário internacional. Lembrando que, primeiramente, teria de haver concordância dentro do próprio bloco, o que é dificultado pelas posições de Rússia e China. A iniciativa que mais chama a atenção nesse tema, por parte do bloco, é o BRICS Cable. A ideia é de que seja construída uma rede de cabos submarinos de fibra óptica que conecte os países do bloco, mais os Estados Unidos e Cingapura. O projeto surgiu antes das revelações de Snowden em 2013, mas foram encontradas grandes dificuldades em descobrir a atual situação do projeto, que parece ter sido "enterrado" por falta de financiamento (que, supõe-se, partiria do Banco dos BRICS). O discurso que permeou o projeto tratava exatamente da oposição à hegemonia ocidental, 
na tentativa de proteção de dados, uma espécie de medida "anti-espionagem". Andrew Mthembu, um dos nomes por trás do BRICS Cable, pela África do Sul, declarou: "There is a growing wariness among these countries that when their data traffic goes through hubs in Europe or the U.S., it incurs a greater "risk of potential interception of critical financial and security information by non-BRICS entities" (ROLLAND, 2015).

\section{Conclusão}

Fica evidente o protagonismo estatal, ainda que os Estados causem um certo "atraso" no avanço de uma governança global. Afinal, a Internet e as tecnologias de informação e comunicação em geral podem ser consideradas como um novo poder de coerção dos governos. Assim, o caráter multistakeholder, ou multissetorial, se mostra cada vez mais importante para a evolução do ecossistema da Internet.

Resta, portanto, expectativas de como esse tema terá continuidade a partir das trocas de governos, tanto no Brasil (governo Temer) quanto nos Estados Unidos (o mandato de Obama se encerra esse ano). É certo, ao menos, que organizações e sociedade civil continuem lutando por uma Internet mais aberta e unificada mundialmente.

\section{Referências Bibliográficas}

CÂMARA. Relatório Final da CPI de Crimes Cibernéticos, 30 mar 2016. Disponível em: $<$ http://www.camara.gov.br/proposicoesWeb/prop_mostrarintegra?codteor=1447125\&filen ame=Tramitacao-RCP+10/2015>. Acesso em 3 abr 2016.

CHADE, J. País tenta emplacar resolução, mas não obtém sucesso. Estadão, São Paulo. 7 set. 2013. 
CGI. Nota de esclarecimento em razão do Relatório da CPI - Crimes Cibernéticos. CGI.br. Disponível em: <http://cgi.br/esclarecimento/nota-de-esclarecimento-em-razao-dorelatorio-da-cpi-crimes-ciberneticos/> . Acesso em 09 abr 2016.

CONVERGÊNCIA DIGITAL. Fim da gestão do Governo dos EUA abre nova era para a Internet, 4 out 2016. Disponível em: $<$ http://convergenciadigital.uol.com.br/cgi/cgilua.exe/sys/start.htm?UserActiveTemplate=s ite\&infoid $=43677 \&$ sid=4 $>$. Acesso em 12 out 2016.

FERREIRA, C. Discurso de Dilma na ONU traduz a Nova Política Externa. Carta Capital, 30 set 2014. Disponível em: <http://www.cartacapital.com.br/blogs/blog-do-grri/discursode-dilma-na-onu-traduz-a-nova-politica-externa-7051.html>. Acesso em 10 out 2016.

FOLHA. Brasil se alinha a China e Irã em leis da internet, 7 jan 2013. Disponível em: $<$ http://www1.folha.uol.com.br/colunas/ronaldolemos/1210826-brasil-se-alinha-a-china-eira-em-leis-da-internet.shtml >. Acesso em 13 out 2016.

FUNAG. Presidenta da República, Dilma Rousseff, durante cerimônia de Lançamento do Pacto Nacional de Enfrentamento às Violações de Direitos Humanos na Internet, Brasília, 7 abr 2015. Repertório de Política Externa, 2016. Disponível em: <http://funag.gov.br/ipri/index.php/noticias/641-repertorio-de-politica-externa-2015>. Acesso em: 1 mar. 2016.

ITU. Final Acts Of The World Conference On International Telecommunications. Dubai, 2012. Disponível em: 〈http://www.itu.int/en/wcit-12/documents/final-acts-wcit-12.pdf $>$. Acesso em 21 maio 2016.

MINISTÉRIO DA JUSTIÇA. Marco Civil da Internet. Pensando o Direito. Disponível em: <http://pensando.mj.gov.br/marcocivil/>. Acesso em 1 mar 2016.

MUGGAH; GLENN; DINIZ. Securitização da Cibersegurança no Brasil. Cadernos Adenauer XV, nº 4, 2014.

MUGGAH; GLENNY. Why Brazil Put Its Military In Charge of Cyber Security. Defense One, 13 jan 2015. Disponível em: <http://www.defenseone.com/technology/2015/01/whybrazil-put-its-military-charge-cyber-security/102756/>. Acesso em 14 mar 2016.

O GLOBO. Dilma disse que Obama em vez de espionar, ligará para ela se quiser saber de algo, 11 abr 2015. Disponível em: <http://oglobo.globo.com/mundo/dilma-disse-que- 
obama-em-vez-de-espionar-ligara-para-ela-se-quiser-saber-de-algo-15849140>. Acesso em 28 mar 2016.

ONU BRASIL. Sob liderança de Brasil e Alemanha, ONU cria mandato de relator sobre privacidade na era digital. ONU Brasil, 30 mar 2015. Disponível em:

$<$ https://nacoesunidas.org/sob-lideranca-de-brasil-e-alemanha-onu-cria-mandato-derelator-sobre-privacidade-na-era-digital/> . Acesso em 30 mar 2016.

PB AGORA. Especialistas destacam debates do Fórum de Governança da Internet, 15 nov 2015. Disponível em:

<http://www.pbagora.com.br/conteudo.php?id=20151115153653\&cat=paraiba\&keys=espe cialistas-destacam-debates-forum-governanca-internet>. Acesso em 1 mar 2016.

PORTAL BRASIL. Parceria entre governo brasileiro e Facebook vai ampliar inclusão digital no País. Disponível em: <http://www.brasil.gov.br/governo/2015/04/dilma-ezuckerberg-conversam-sobre-inclusao-digital-e-conectividade-no-panama>. Acesso em 6 maio 2016.

PORTAL G1. Anonymous ataca sites ligados ao governo em protesto contra a Rio+20, 20 jun 2012. Disponível em: <http://g1.globo.com/tecnologia/noticia/2012/06/anonymousataca-sites-ligados-ao-governo-em-protesto-contra-rio20.html>. Acesso em 1 mar 2016.

Na Rio+20, Exército testa estratégias de defesa virtual em grandes eventos, 30 maio 2012. Disponível em: <http://g1.globo.com/tecnologia/noticia/2012/05/na-rio20exercito-testa-estrategias-de-defesa-virtual-em-grandes-eventos.html >. Acesso em 1 mar 2016.

WhatsApp bloqueado: operadoras são intimadas a barrar app no país por 48h, 16 dez 2015. Disponível em: <http://g1.globo.com/tecnologia/noticia/2015/12/operadorassao-intimadas-bloquear-whatsapp-no-brasil-por-48-horas.html>. Acesso em 14 mar 2016.

PRESIDÊNCIA DA REPÚBLICA. Lei do Marco Civil da Internet no Brasil. Brasília, 23 abr. 2014. Disponível em: 〈http://www.cgi.br/lei-do-marco-civil-da-internet-no-brasil/> Acesso em: 20 mai. 2015.

ROLLAND, N. A Fiber-Optic Silk Road. The Diplomat, 2 abr 2015. Disponível em: <http://thediplomat.com/2015/04/a-fiber-optic-silk-road/>. Acesso em 19 abr 2016. 
ROUSSEFF, D. Discurso da Presidenta da República, Dilma Rousseff, na abertura do Debate de Alto Nível da 69a Assembleia Geral das Nações Unidas (ONU). Planalto.gov, 24 set 2014. Disponível em: <http://www2.planalto.gov.br/acompanhe-o-

planalto/discursos/discursos-da-presidenta/discurso-da-presidenta-da-republica-dilmarousseff-na-abertura-do-debate-de-alto-nivel-da-69a-assembleia-geral-das-nacoes-unidasonu>. Acesso em 28 mar 2016.

TED TALKS. Julian Assange: por que o mundo precisa do Wikileaks. TED, Youtube, 19 jul 2010. Disponível em: <https://www.youtube.com/watch?v=HNOnvp5t7Do>. Acesso em 30 mar 2016.

THE GUARDIAN. Brazilian president: US surveillance a 'breach of international law', 24 set 2013. Disponível em: <http://www.theguardian.com/world/2013/sep/24/brazilpresident-un-speech-nsa-surveillance>. Acesso em 16 mar 2016.

TV NBR. Em discurso na ONU, Dilma defende marco civil global e garantia de proteção de dados para a internet. TV NBR, Youtube, 24 set 2013. Disponível em:

<https://www.youtube.com/watch?v=7TqNk5fMd_8>. Acesso em 28 mar 2016. 